\title{
Systematic review of persistent pain and psychological outcomes following traumatic musculoskeletal injury
}

This article was published in the following Dove Press journal: Journal of Pain Research

9 January 2013

Number of times this article has been viewed

\author{
Brittany N Rosenbloom' \\ Sobia Khan ${ }^{2}$ \\ Colin McCartney ${ }^{3}$ \\ Joel Katz ${ }^{4}$ \\ 'Institute of Medical Science, \\ University of Toronto, Toronto, \\ Ontario, ${ }^{2}$ School of Public Health \\ and Health Systems, University \\ of Waterloo, Waterloo, Ontario, \\ ${ }^{3}$ Department of Anesthesia, \\ Sunnybrook Health Sciences Centre, \\ Toronto, Ontario, ${ }^{4}$ Department of \\ Psychology, York University, Toronto, \\ Ontario, Canada
}

Background: Persistent pain and psychological distress are common after traumatic musculoskeletal injury (TMsI). Individuals sustaining a TMsI are often young, do not recover quickly, and place a large economic burden on society.

Objectives: The aim of this systematic review is to determine (1) the incidence of persistent pain following TMsI, (2) the characteristics of pain, characterized by injury severity and type, and (3) risk and protective factors associated with persistent pain following TMsI.

Methods: A systematic search of electronic databases $\left(\right.$ MEDLINE $^{\circledR}$, PubMed $^{\circledR}$, Embase, and PsycINFO ${ }^{\circledR}$ ) was conducted for prospective, interventional, or noninterventional studies measuring the incidence of pain associated with TMsI.

Results: The search revealed 4388 studies. Eleven studies examined persistent pain and met inclusion criteria. Pain was assessed using a validated measure of pain intensity or pain presence in six studies. Persistent pain was reported by all studies at variable time points up to 84 months postinjury, with wide variation among studies in pain intensity (ie, from mild to very severe) and pain incidence at each time point. The incidence of pain decreased over time within each study. Two studies found significant relationships between injury severity and persistent pain. Frequently cited predictive factors for persistent pain included: symptoms of anxiety and depression, patient perception that the injury was attributable to external sources (ie, they were not at fault), cognitive avoidance of distressing thoughts, alcohol consumption prior to trauma, lower educational status, being injured at work, eligibility for compensation, pain at initial assessment, and older age.

Conclusion and implications: The evidence from the eleven studies included in this review indicates that persistent pain is prevalent up to 84 months following traumatic injury. Further research is needed to better evaluate persistent pain and other long-term posttraumatic outcomes.

Keywords: persistent pain, psychological outcomes, traumatic injury, musculoskeletal, systematic review, pain intensity, injury severity, risk and protective factors

Brittany N Rosen M3-200 2075 Bayview Ave, Sunnybrook Health Sciences Center, Toronto, ON M4N 3M5, Canada

$\mathrm{Tel}+\mathrm{I} 4164806100$ ext 89607

Fax + I 4164806039

Email brittany.rosenbloom@mail.

utoronto.ca

Joel Katz

Department of Psychology, BSB 232, York University, 4700 Keele Street, Toronto,

ON M3J IP3, Canada

Tel +I 4167362100 ext 40557

Email jkatz@yorku.ca

\section{Introduction}

Traumatic injury is the leading cause of death and morbidity worldwide among individuals under the age of 45 years and is the fourth leading cause of death for all age groups. ${ }^{1,2}$ The majority of traumatic injuries are caused by falls, motor vehicle accidents, homicide or injury purposely inflicted by another person, or self-inflicted injury. ${ }^{1,3}$ In 2008, 5.13 million deaths occurred worldwide as a result of traumatic injury, with mortality as a result of road accidents being one of the top ten causes of death across the globe. ${ }^{2}$ Of those individuals that survive, approximately $16 \%$ acquire 
a long-term disability. ${ }^{1,3}$ It is apparent that traumatic injury is a serious clinical and public health concern.

Orthopedic injuries are the most common type of injury, ${ }^{4}$ can involve more than one body region, ${ }^{5}$ and may require multiple surgical interventions. ${ }^{6}$ Although medical advances continue to allow for improved mortality rates related to trauma, a proportion of patients may go on to develop pain beyond the acute phase, ie, develop persistent pain. ${ }^{6-11}$ The definition of persistent pain following traumatic musculoskeletal injury (TMsI) is not clearly defined in the literature; however, for the purposes of this review and consistent with Macrae and Davies's definition of chronic postsurgical pain, persistent pain is defined as: (1) pain that develops after traumatic injury or after surgical intervention in the wake of traumatic injury; (2) pain that has been present for at least
2 months; (3) other causes of pain have been ruled out (eg, further surgical interventions have not occurred); and (4) the possibility that the pain is a continuation of a preexisting problem should be ruled out. ${ }^{12,13}$

Persistent pain often exacerbates psychological distress, with many patients who have sustained a TMsI going on to meet diagnostic criteria for anxiety disorders, including posttraumatic stress disorder (PTSD) and mood disorders such as depression. ${ }^{14-17}$ Thus, despite increased survival rates after traumatic injury, many patients exhibit substantial comorbidities including a diminished quality of life, persistent pain, and an increased risk for psychiatric disorders.

There are a number of factors that impact the development of persistent pain following traumatic injury. As shown in Figure 1, the development of persistent pain and disability

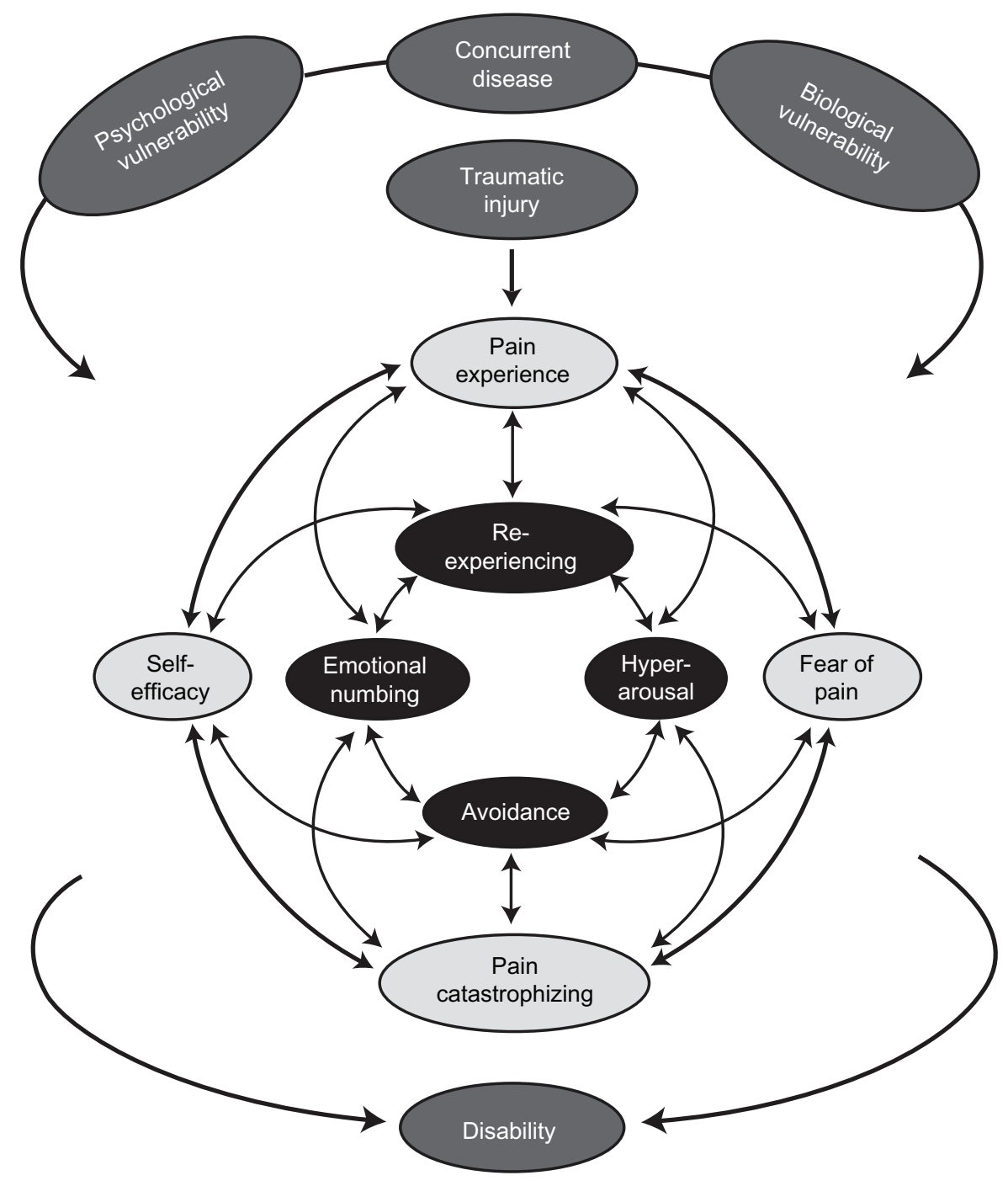

Figure I Combined shared vulnerability and mutual maintenance model of disability in the context of traumatic injury.

Notes: The model depicts the influence that preexisting factors including psychological (eg, anxiety sensitivity) and biological (eg, low threshold for startle response) vulnerabilities and concurrent disease have on traumatic injury and subsequently the mutual maintenance of posttraumatic stress symptoms and pain in the development of persistent pain disability. Single-headed arrows indicate the direction of a temporal relationship between factors; double-headed arrows indicate some of the possible association between factors; not all possible relationships are shown. 
is complex; however, the relationships between preexisting, peritraumatic (ie, time immediately after trauma, during hospitalization for up to 2 weeks after injury), and posttraumatic variables may be explained through a modified diathesis-stress model of chronic pain involving a combination of shared vulnerability and mutual maintenance factors. ${ }^{18}$ According to this model, shared psychological and biological vulnerabilities (diatheses) are presumed to place the individual at an increased risk of developing both persistent pain and PTSD following a traumatic injury. Proposed psychological vulnerabilities include sensitivity to pain traumatization (ie, a propensity to develop anxietyrelated somatic, cognitive, emotional, and behavioral responses to pain that resemble a traumatic stress reaction) and anxiety sensitivity (ie, fear of the symptoms of anxiety due to the belief that they will lead to harmful physical, psychological, and/or social consequences). ${ }^{19-21}$ Proposed biological vulnerability factors include a low threshold for startle and preexisting hypothalamic-pituitary-adrenal axis sensitivity. ${ }^{22}$ These diatheses interact with trauma-related (eg, TMsI) and disease-related stressors (eg, diabetes), which together feed into a mutual maintenance model involving fearavoidance symptoms of persistent pain (ie, pain experience, self-efficacy, a fear of pain, and pain catastrophizing) and symptoms of PTSD (ie, reexperiencing, hyperarousal, avoidance, and emotional numbing). ${ }^{19,20,23,24}$ Because the two disorders show substantial symptom overlap, symptoms of one disorder (eg, an exacerbation of pain) may trigger and maintain symptoms of the other disorder (eg, intrusive thoughts, flashback, hyperarousal, avoidance) and vice versa. The particular pattern of mutual maintenance will differ for each individual depending upon the nature of the traumatic stressor as well as individual differences in the expression of somatic, cognitive, affective, and behavioral factors. The final outcome of the model is increased pain and disability.

Published reviews have assessed the presence of pain as well as other detrimental outcomes following TMsI. These reviews provide valuable information for certain populations of trauma patients (eg, those experiencing head, whiplash, or spinal injuries or burns) $)^{25-29}$ and some summarize predictors of persistent pain. ${ }^{25}$ However, information on the incidence, intensity, and duration of persistent pain following musculoskeletal injury has not been synthesized among prospective, longitudinal studies. Clinicians and researchers can benefit from more detail regarding the characteristics of the pain (ie, intensity and duration of persistent pain) to better treat current patients and develop targeted interventions. Thus, the aim of the present systematic review is to determine
(1) the incidence and duration of persistent pain following TMsI, (2) the intensity of pain, characterized by injury severity and type, and (3) risk and protective factors associated with persistent pain following TMsI.

\section{Methods}

Preferred Reporting Items for Systematic Reviews and Meta-Analyses (PRISMA) guidelines were followed for conducting systematic reviews. ${ }^{30}$

\section{Data sources and searches}

A systematic search of electronic databases (MEDLINE ${ }^{\circledR}$, PubMed $^{\circledR}$, Embase, and PsycINFO ${ }^{\circledR}$ ) was conducted for prospective, interventional, or noninterventional studies published between 1947 and February 2012 measuring the incidence of pain associated with TMsI as the sole outcome, or measuring anxiety disorders (including PTSD) and depression as secondary outcomes in addition to pain. Several search terms were combined using the "OR" operator within each category of trauma ("musculoskeletal trauma," "trauma," "multiple traumas," "injuries," "multiple injuries"), pain ("posttraumatic pain," persistent pain," "chronic pain," "postsurgical pain," "[various bodily regions] pain"), depression ("depression," "brief depression," "chronic depression"), anxiety ("anxiety," "anxiety disorder," "anticipatory anxiety," "mixed anxiety and depression," "death anxiety") and PTSD ("posttraumatic stress disorder"). Categories were combined in the search strategy using the "AND" operator. Where medical subject heading (MeSH) terms and medical headings were unavailable or irrelevant to the search, the common terms were utilized for individual database searches. Reference lists from all identified primary papers and review articles were examined for additional studies.

\section{Study selection}

All article titles and abstracts $(n=4388)$ were independently screened for inclusion by two reviewers (BNR and SK). An interrater reliability analysis using Kappa statistic was performed to determine consistency among raters. Discrepancies between the reviewers were resolved through consensus or involvement of a third reviewer (JK or CM). Inclusion criteria were: prospective studies; studies examining individuals who had experienced TMsI; studies measuring pain intensity at initial assessment and again at 3 months or more postinjury; and studies including individuals aged 16 years or older. These studies may have also included measures of anxiety, depression, and/or PTSD. Exclusion criteria were studies investigating: pediatric populations aged less than 16 years 
due to differences in physiology and pain assessment measures utilized; moderate to severe brain injury; spinal cord damage; burns to $>30 \%$ of body surface; and self-injurious patient populations. Dissertations, abstracts only, guidelines, reviews, unpublished abstracts, and non-English articles were also excluded.

Following abstract screening, studies meeting eligibility criteria were subjected to a full text review. Articles were also retrieved for abstracts that did not provide enough information for inclusion/exclusion at the first stage of screening. Studies failing to meet eligibility criteria after full text review were excluded.

\section{Data extraction}

A systematic approach was taken to extract data from selected articles using a data extraction tool developed by the two reviewers (BNR and SK) to summarize means, standard deviations, ranges, percentages, and other reported statistical results. Data extracted from included studies are summarized in Table 1.

Risk of bias was assessed independently by two reviewers (BNR and SK) using the Downs and Black critical appraisal tool. ${ }^{31}$ Because not one randomized controlled trial met inclusion criteria for this review, nine items relating specifically to randomized controlled trials were omitted and the 27 -item tool with a total possible score of 32 was reduced to 18 items with a total possible score of 23 . Interrater reliability for the two raters was perfect with total agreement for all studies.

\section{Results}

The systematic database search yielded 4388 abstracts. Forty-seven abstracts were identified for potential inclusion.

Table I Variables extracted from articles included in the present review

\begin{tabular}{l}
\hline Variable information extracted \\
\hline Patient characteristics \\
Sample size \\
Injury severity scale scores \\
Hospital length of stay \\
Pain intensity \\
Pain duration \\
Pain frequency \\
Injury type \\
Injury mechanisms \\
Predictive factors for persistent pain \\
Pain outcome measures used to determine pain intensity or incidence \\
Other variables assessed, ie, anxiety (posttraumatic stress disorder), \\
depression, that are associated with, or predict the development of, \\
persistent pain
\end{tabular}

Abbreviation: ISS, Injury Severity Scale; LOS, Length of stay; PTSD, Posttraumatic Stress Disorder.
After full text review, eleven studies met inclusion criteria and one study required additional information regarding the timing of interventions to determine its eligibility for inclusion. Attempts were made via email to contact the corresponding author of this study; ${ }^{32}$ however, because the author was unable to be reached, the article was excluded from further analysis. The interrater reliability for the raters was found to be Kappa $=0.938(P<0.000)$. Thus, eleven studies were included in the current review (Figure 2). Details of each of the eleven included studies are presented in Table 2.

\section{Risk of bias}

The median quality score for the eleven studies was 21 (range 18-23). Overall, risk of bias was minimized across studies by adequately describing hypotheses, primary outcomes, and study inclusion and exclusion criteria. Two studies had very low risk of bias (ie, a perfect score). ${ }^{33,34}$ Two studies notably did not have defined hypotheses, nor did they describe their primary outcomes of interest clearly. ${ }^{35,36}$ One study did not clearly describe the main findings or include measures of variability. ${ }^{37}$ Another study did not describe loss to follow-up. ${ }^{38}$ Two studies did not provide actual $P$-values for probabilities less than $0.05 .{ }^{35,36}$ Two studies stated that they collected patient demographic data but did not report these, ${ }^{37,39}$ and three studies did not report demographic data adequately. ${ }^{35,36,40}$

\section{Study characteristics}

This review included 4386 participants from eleven studies. Sample sizes for each study ranged from 90-1290 participants with ages of participants ranging 16-95 years. Assessments of participants following TMsI included an initial assessment close to the time of injury (during hospitalization) and again at 3-4 months, 6 months, 8 months, 12 months, 36 months, 36 months, and 84 months after TMsI. The majority of injuries included in these studies were caused by motor vehicle accidents, falls, assaults, and recreational-related accidents and resulted in injury severity scores of zero to 19 with the length of hospital stay ranging from no admission to 15 days in hospital.

\section{Pain measurement}

Pain was assessed peritraumatically (ie, time immediately after trauma, during hospitalization for up to 2 weeks after injury) and again at various time points following TMsI using a validated measure of pain intensity or pain presence/absence in six studies and/or as part of a more general quality of life questionnaire in five studies (Table 3 ). In each of the six 


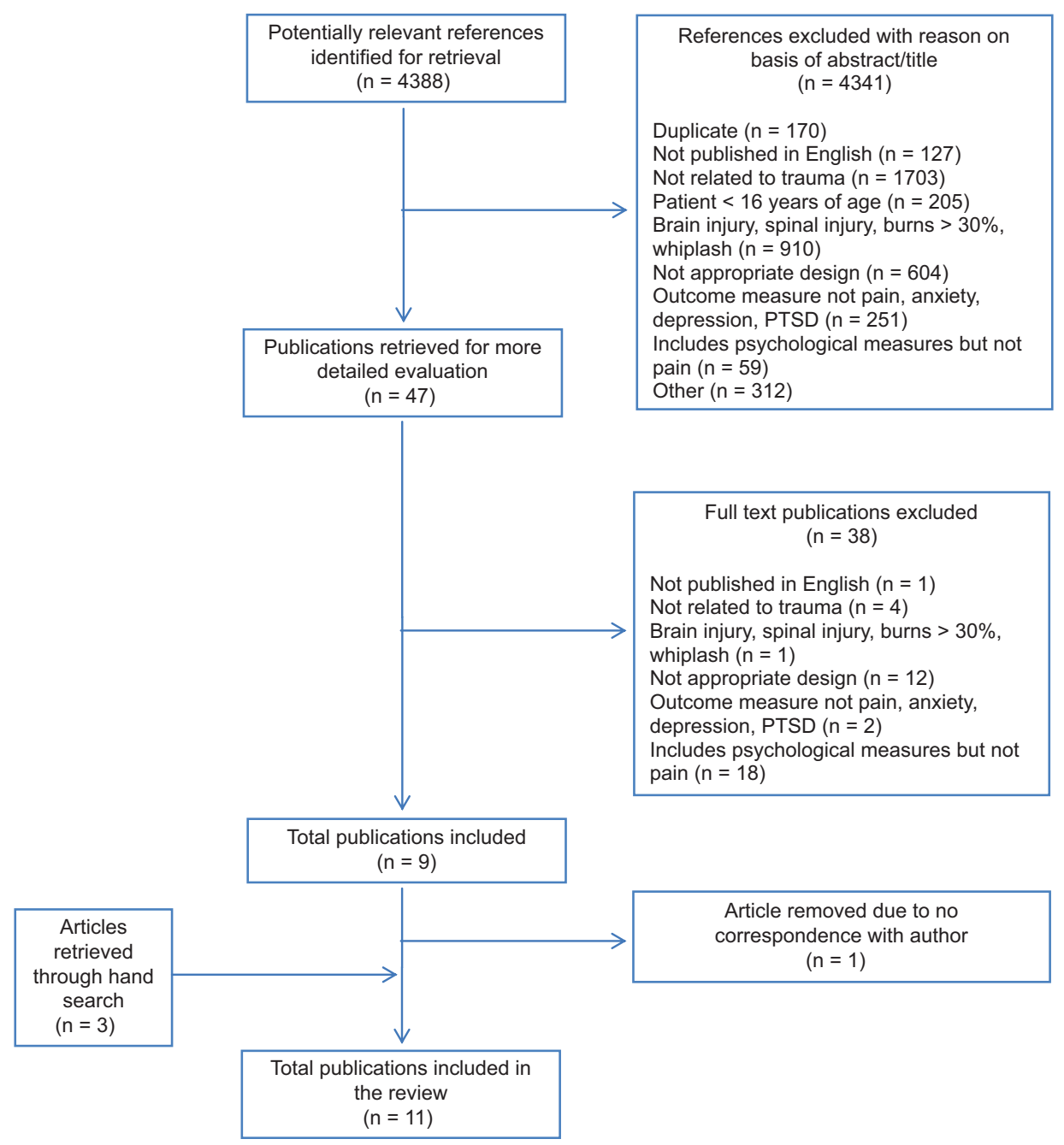

Figure 2 Preferred Reporting Items for Systematic Reviews and Meta-Analyses (PRISMA) flow diagram showing details of the studies included and excluded in the current review.

Abbreviation: PTSD, posttraumatic stress disorder.

studies that included validated measures of pain, pain intensity was measured using either a $10 \mathrm{~cm}$ or $100 \mathrm{~mm}$ visual analog scale or a zero to ten point numeric rating scale. Two of these studies also used comprehensive measures of pain in addition to a visual analog scale or numeric rating scale, including either the McGill Pain Questionnaire or Short-Form McGill Pain Questionnaire. ${ }^{38,41}$ One study used only the Graded Chronic Pain Scale. ${ }^{39}$ In the five studies that did not utilize validated measures specifically for pain, two studies used the bodily pain question from the Short Form-36 (SF-36), ${ }^{34,42}$ two studies used the Short Form-6 (SF-6), ${ }^{35,36}$ and one study asked participants if they had pain related to the trauma. ${ }^{33}$

\section{Incidence and duration of pain posttrauma}

Ten of eleven studies reported incidence of pain and pain intensity (Table 3). Overall, results were highly heterogeneous.
All studies reported follow-ups and reported either pain intensity or pain incidence but the follow-up times varied considerably from 3-84 months after injury (Table 3). The percentage of patients experiencing pain varied considerably between studies, ranging from 28\%-93\% of participants reporting mild to severe pain after initial assessment. Overall, the incidence of patients reporting pain decreased over time within each study. ${ }^{35,36,40-43}$

\section{Intensity of pain posttrauma}

Relationship between injury severity and pain intensity The severity of injury varied across the eleven studies. Seven of the eleven studies statistically assessed the association between injury severity, as measured by the Injury Severity Score (ISS) and pain at initial assessment and/or at follow-up time points..$^{33,35-37,41-43}$ Two of the seven 
Table 2 Demographic characteristics from each of the eleven studies included in the present review

\begin{tabular}{|c|c|c|c|c|}
\hline Author & $\begin{array}{l}\text { Study } \\
\text { location }\end{array}$ & $\begin{array}{l}\text { Sample size } \\
\text { (n, \% male) }\end{array}$ & $\begin{array}{l}\text { Age } \\
\text { (mean, SD, range) }\end{array}$ & $\begin{array}{l}\text { Length of stay, days } \\
\text { (mean, SD) }\end{array}$ \\
\hline Aitken et $\mathrm{al}^{34}$ & $\begin{array}{l}\text { Queensland, } \\
\text { Australia }\end{array}$ & 194 (66\% male) & 39 (range 29-56) & 8.5 (range $5-15$ ) \\
\hline Castillo et $\mathrm{a}^{39}$ & Texas, USA & 397 & NR & NR \\
\hline Clay et $\mathrm{a}^{41}$ & $\begin{array}{l}\text { Victoria, } \\
\text { Australia }\end{array}$ & 150 & 37.7 (range 18-62) & NR \\
\hline Holmes et $\mathrm{al}^{37}$ & $\begin{array}{l}\text { Melbourne, } \\
\text { Australia }\end{array}$ & $290(75.9 \%$ male $)$ & NR & $10.8(10.0)$ \\
\hline Jenewein et $\mathrm{al}^{33}$ & $\begin{array}{l}\text { Zurich, } \\
\text { Switzerland }\end{array}$ & 90 & $41.9(S D=13.2)$ & NR \\
\hline $\begin{array}{l}\text { Mayou and } \\
\text { Bryant }^{35}\end{array}$ & Oxford, UK & 507 (55\% male) & $\begin{array}{l}\text { Range 17-69;596 were under the } \\
\text { age of } 30 ; 552 \text { were over the age of } 30\end{array}$ & $\begin{array}{l}\text { Not admitted or no injury = 905; admitted } \\
I-2 \text { nights = I37; admitted } 3+\text { nights }=106\end{array}$ \\
\hline $\begin{array}{l}\text { Mayou and } \\
\text { Bryant }^{36}\end{array}$ & Oxford, UK & II 48 (55\% male) & $\begin{array}{l}596 \text { were under the age of } 30 \\
552 \text { were over the age of } 30\end{array}$ & $\begin{array}{l}\text { Not admitted or no injury }=905 ; \text { admitted } \\
\mathrm{I}-2 \text { nights }=137 \text {; admitted } 3+\text { nights }=106\end{array}$ \\
\hline Michaels et $\mathrm{al}^{42}$ & USA & 165 (67\% male) & $37.2(\mathrm{SD}=1.1)$ & $9.6(0.9)$ \\
\hline Norman et $\mathrm{a}^{38}$ & $\begin{array}{l}\text { California, } \\
\text { USA }\end{array}$ & II 5 (63\% male) & 36 & NR \\
\hline Sanders et $\mathrm{al}^{40}$ & $\begin{array}{l}\text { London, } \\
\text { Canada }\end{array}$ & 40 (85\% male) & 29 (range 17-65) & NR \\
\hline Williamson et $\mathrm{al}^{43}$ & Australia & $1290(6 \mid \%$ male $)$ & Range 14-95 & 7 (range $3-13$ ) \\
\hline
\end{tabular}

Abbreviations: ISS, Injury Severity Scale; LE, lower extremity; MVA, motor vehicle accident; NR, not reported; ORTHO, orthopedic injury; SD, standard deviation; UE, upper extremity.

studies found significant relationships between injury severity and persistent pain. ${ }^{36,43}$ Specifically, Williamson et al reported that patients with an ISS of greater than 15 (ie, patients with a major traumatic injury) were 1.7 times more likely (confidence interval: $1.3-2.3, P<0.001$ ) to have pain 6 months later than those patients with an ISS of 15 or less. ${ }^{43}$ However, upon addition of ISS to a regression model used to predict persistent pain at 6 months postinjury, with educational status, markers of preinjury anxiety, depression, and pain-related disability, compensation status, and pain score at discharge as covariates, ISS was no longer a significant predictor of persistent pain. ${ }^{43}$ Mayou and Bryant did not find an association between ISS and persistent pain; however, when classifying injury severity among those patients with medically serious injuries (ie, those in hospital for 3 days or more due to the severity of their injuries), a significant difference was found such that a higher proportion of patients with medically serious injuries reported moderate to severe pain or severe pain at 3 months $(57 \%$ versus $24 \% ; P<0.001)$ and at 1 year following injury $(36 \%$ versus $20 \% ; P<0.01)$ compared to non-medically serious injury patients. ${ }^{36}$

\section{Relationship between injury type and pain intensity}

Eight studies assessed the association between injury type and persistent pain following traumatic injury. ${ }^{34,36,37,39-43}$ The definition of injury type varied between studies with some defining injuries by specific (eg, tibia) or general (eg, lower extremity, upper extremity) body location, number (eg, isolated, multiple), and/or type (eg, amputation, fracture, general orthopedic injuries).

Five of the eight studies assessing injury type and persistent pain found significant relationships between the 


\begin{tabular}{|c|c|c|c|}
\hline $\begin{array}{l}\text { ISS score } \\
\text { (mean, SD, range) }\end{array}$ & Mechanism of injury (\%) & Injury type (\%) & $\begin{array}{l}\text { Risk } \\
\text { of bias }\end{array}$ \\
\hline 9 (range 5-14) & $42 \%$ MVA; $32 \%$ falls; II $\%$ collisions; $15 \%$ other & $\begin{array}{l}50 \% \text { LE; I } 8 \% \text { UE; I } 2 \% \text { thorax; II } \% \text { head, face, } \\
\text { and neck; } 5 \% \text { spine; and } 4 \% \text { pelvis/abdomen }\end{array}$ & 22 \\
\hline NR & NR & $\begin{array}{l}19.6 \% \text { salvage tibia fractures; } 28.7 \% \text { articular } \\
\text { fractures; II.1\% foot fractures; } 13.8 \% \text { soft } \\
\text { tissue injuries; } 1.7 \% \text { foot amputations; } 16.8 \% \\
\text { below knee amputations; } 3.7 \% \text { through knee } \\
\text { amputations; } 7.0 \% \text { above knee amputations }\end{array}$ & 21 \\
\hline $\begin{array}{l}88 \text { participants with minor } \\
\text { injuries (ISS I-8), } 69 \text { with } \\
\text { moderate injuries (ISS 9-I5), } \\
\text { and II with major injuries } \\
(\text { ISS }>\text { I6) }\end{array}$ & $66.6 \%$ MVA or during employment & $\begin{array}{l}3.6 \% \text { spinal injuries only; } 24.4 \% \text { isolated } \\
\text { LE injury; } 19.6 \% \text { isolated UE injuries; } 17.8 \% \\
\text { multiple LE injuries; } 5.4 \% \text { multiple UE injuries } \\
\text { I8.4\% ORTHO injuries - multiple regions; } \\
\text { I0.7\% ORTHO and other injuries }\end{array}$ & 23 \\
\hline $12.3(\mathrm{SD}=8.5)$ & $57.6 \%$ MVA; $12.4 \%$ falls; $6.2 \%$ assaults & $\begin{array}{l}\text { Injuries occurred predominantly } \\
\text { in the extremities and chest }\end{array}$ & 21 \\
\hline NR & $\begin{array}{l}58.9 \% \text { MVA; } 21.1 \% \text { sports and leisure-time accidents; } \\
14.4 \% \text { during employment; } 5.6 \% \text { household accidents }\end{array}$ & NR & 23 \\
\hline $\begin{array}{l}\text { Range } 0-19 \\
(n=216 \text { over } 4)\end{array}$ & $\begin{array}{l}52 \% \text { MVA - driver; } 21 \% \text { MVA - passenger; } \\
12 \% \text { motorcyclist; II\% cyclist; } 4 \% \text { pedestrian }\end{array}$ & NR & 18 \\
\hline $\begin{array}{l}\text { Range } 0-19 \\
(n=216 \text { over } 4)\end{array}$ & $\begin{array}{l}52 \% \text { MVA - driver; } 21 \% \text { MVA - passenger; } \\
\text { I2\% motorcyclist; II\% cyclist; } 4 \% \text { pedestrian }\end{array}$ & NR & 18 \\
\hline $14.4(\mathrm{SD}=0.6)$ & NR & $\begin{array}{l}61 \% \text { ORTHO injury; } 66 \% \text { multiple ORTHO } \\
\text { injuries; } 62 \% \text { had LE ORTHO injuries }\end{array}$ & 22 \\
\hline NR & $\begin{array}{l}66 \% \text { MVA; } 5 \% \text { burns; } 6 \% \text { falls; } 4 \% \text { occupational } \\
\text { injuries; } 3 \% \text { recreational injuries (eg, jet skiing); } \\
10 \% \text { stab wounds; } 10 \% \text { gunshot wounds; } 3 \% \text { assault }\end{array}$ & NR & 18 \\
\hline NR & $\begin{array}{l}72.5 \% \text { MVA; } 10 \% \text { recreational/sports injuries; } \\
17.5 \% \text { falls }\end{array}$ & Isolated diaphyseal fractures of the femur & 18 \\
\hline $\begin{array}{l}\text { ISS was reported in lump } \\
\text { above } 15 \text { and below } 15 \text { in } \\
\text { an odds ratio analysis }\end{array}$ & $\begin{array}{l}52 \% \text { MVA; } 34 \% \text { falls; } 1.5 \% \text { horse-related activities; } \\
0.2 \% \text { firearms injuries; } 18 \% \text { household injuries }\end{array}$ & $\begin{array}{l}24 \% \text { isolated LE injuries; } 7.9 \% \text { isolated UE; } 9.5 \% \\
\text { multiple LE injuries; } 3.7 \% \text { multiple UE injuries; } 5.0 \% \\
\text { spinal injuries; } 5.6 \% \text { multiple ORTHO injuries; } \\
44 \% \text { ORTHO and other injuries }\end{array}$ & 21 \\
\hline
\end{tabular}

two variables, ${ }^{34,40-43}$ whereas three studies did not. ${ }^{36,38,39}$ Specifically, Williamson et al found that patients with orthopedic injuries plus other injuries were $8 \%$ more likely than the general trauma population to have moderate to severe pain 6 months following injury (95\% confidence interval: 3-12) ${ }^{43}$ In contrast, Michaels et al reported that orthopedic injury patients had lower SF-36 bodily pain scores (ie, more intense pain) at 6 months (44.0 versus 56.2) and at 1 year (66.5 versus 79.0) following injury compared to nonorthopedic injury patients. ${ }^{42}$ The trend for severe and persistent pain is greater amongst patients with isolated or multiple orthopedic lower extremity injuries as compared to patients with upper extremity injuries. ${ }^{34,40,41}$ However, another study failed to find a significant relationship between specific lower extremity injury types (eg, tibia fractures versus pelvic fractures) and the presence of persistent pain 7 years posttrauma. ${ }^{39}$

\section{Predictive factors for incidence of pain and pain intensity}

Five of the eleven studies examined variables during the initial assessment period to predict the presence of persistent pain following traumatic injury. ${ }^{35,37,39,41,43}$ One of the five studies evaluated whether these factors predicted both the presence and intensity of persistent pain. ${ }^{41}$

As shown in Table 4, frequently cited predictive factors for persistent pain included: symptoms of anxiety and depression as measured by the Brief Symptom Inventory and the Depression, Anxiety, and Stress Scale-21 (DASS-21), ${ }^{39,41}$ patient perception that the injury was attributable to external sources (ie, they were not at fault), ${ }^{41}$ cognitive avoidance of distressing thoughts, ${ }^{35}$ alcohol consumption prior to trauma, ${ }^{37,39}$ lower educational status, ${ }^{39,43}$ being injured at work, ${ }^{41}$ eligibility for compensation, ${ }^{35,43}$ pain at initial assessment, ${ }^{37,39,41,43}$ and older age. ${ }^{37,41}$ In addition, 


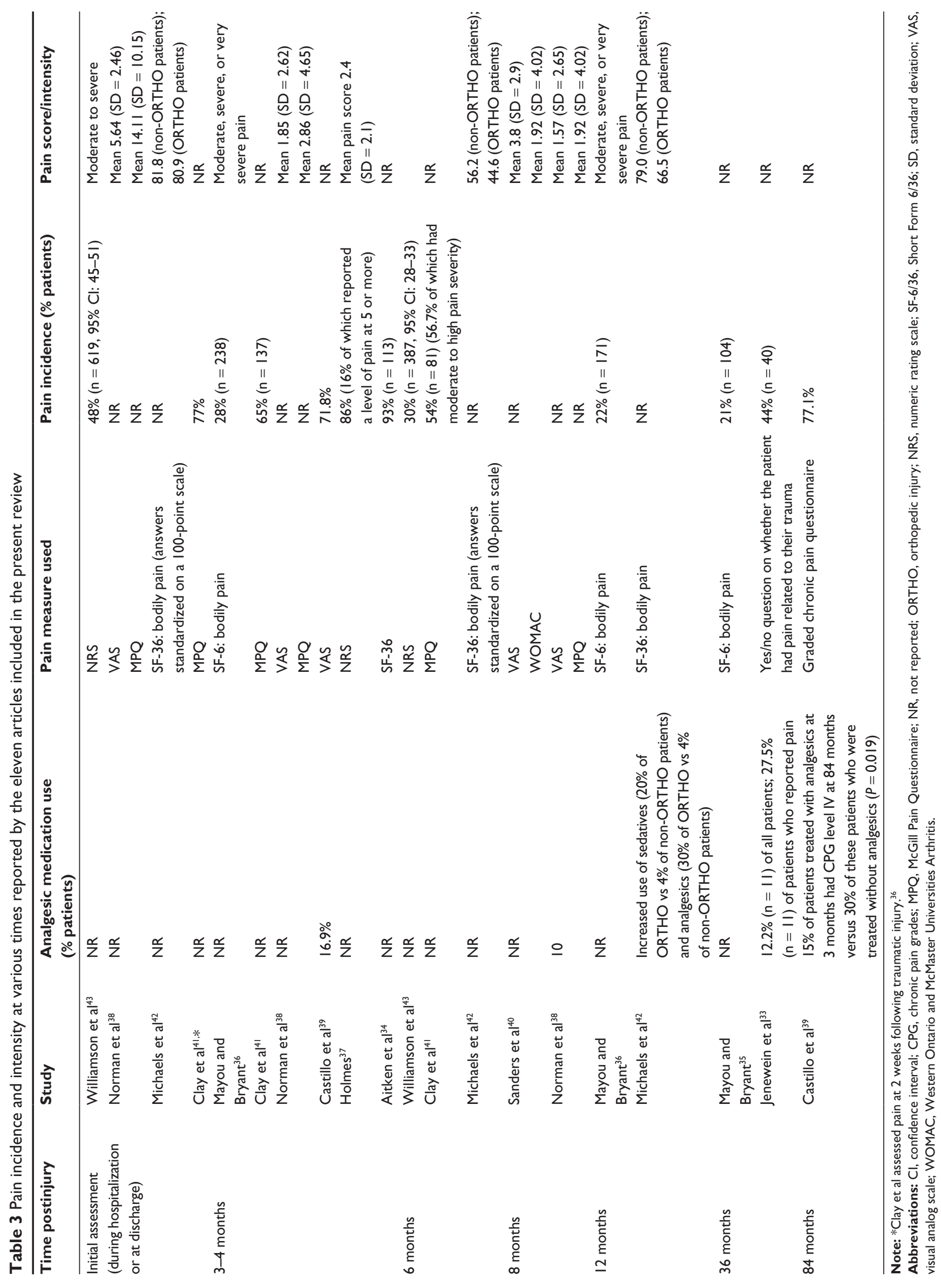




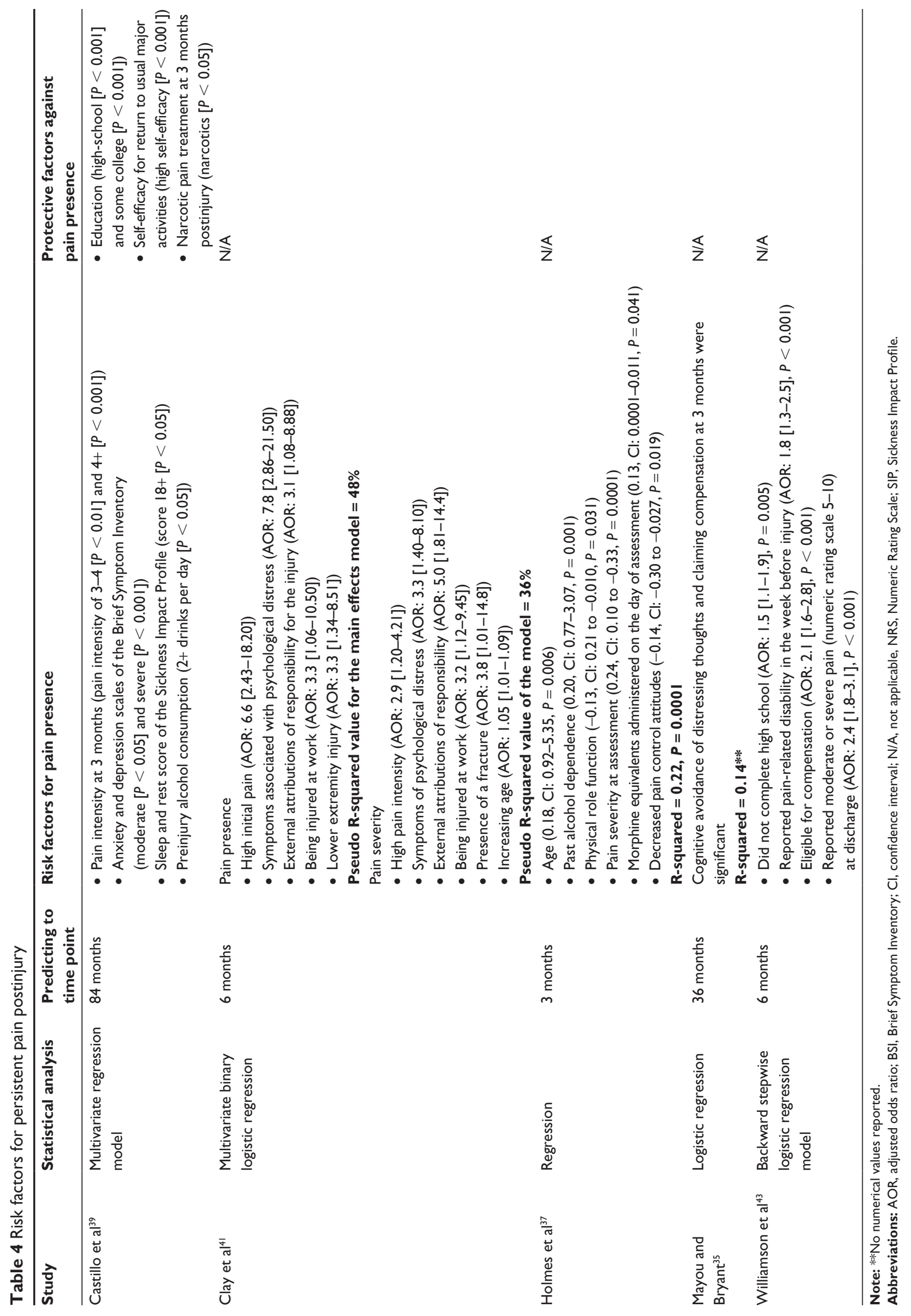


Castillo et al found that pain, as well as sleep and rest irregularities, at 3 months postinjury predicted the presence of persistent pain at 84 months postinjury. ${ }^{39}$

\section{Discussion}

\section{Pain incidence, characteristics, and predictors of pain}

This is the first review to systematically identify prospective studies that measure the incidence of pain following traumatic injury and attempt to understand the theoretical framework including biological, cognitive, and psychological social factors associated with persistent pain. The findings demonstrate that persistent pain is present from 3-84 months following traumatic injury, although incidence of pain was highly variable across studies. There is an overall trend of decreasing pain intensity over time. There is also a trend towards a strong association between injury type and persistent pain, particularly with multiple, orthopedic, lower extremity injuries being linked to persistent pain. The current synthesis demonstrates that the relationship between injury severity and persistent pain is weak, although this relationship was only explored in two studies.

In the five of eleven studies that assessed factors predicting persistent pain, the most consistently reported factors significantly predictive of persistent pain included alcohol consumption prior to traumatic injury, peritraumatic pain, peritraumatic anxiety and depression, eligibility for compensation, lower educational status, and older age. Recently, Clay et al synthesized similar prognostic factors of pain; however, they included retrospective study designs as well as patients with head injuries. ${ }^{25}$ Given the growing number of studies identifying traumatic brain injury as independently associated with pain related to headaches, ${ }^{26,44}$ the current review excluded this population so as to identify the incidence of persistent pain in the absence of head trauma. In doing so, the current review included an additional six studies not included by Clay et $\mathrm{al},{ }^{25}$ and it further helps to elucidate the need for future studies to investigate the development of persistent pain in the TMsI patient population as well as the need for current interventions for patients at present.

\section{Reporting of outcomes and other pertinent information related to pain incidence and intensity}

Across some studies included in the current review, there appeared to be a lack of comprehensive reporting of outcomes that are key to understanding the development of persistent pain following TMsI. The current review is different from other reviews on traumatic injury and persistent pain because studies that indicated some form of initial pain assessment as close as possible to time of injury (eg, during hospitalization) were purposely included. Consideration of initial pain intensity close to the time of injury can help to better determine which patients may be at higher risk of developing persistent pain, and how the characteristics of pain change over time. However, only three studies reported the results of initial pain assessment measurements; the remaining studies indicated that these initial assessments were made but did not report values. Furthermore, some studies did not report metrics that would have provided useful information (odds ratios, regression coefficients, correlation coefficients, significance values) to researchers and clinicians regarding the incidence of persistent pain.

An additional point of consideration is the impact of analgesic use on pain scores. Given the injury type and severity of many of the patients in the included reviews, it was likely that these patients were on high-dose opioids while hospitalized, and could have been using analgesics long-term to cope with persistent pain. This may have affected the reporting of pain incidence and intensity at initial assessment and follow-up. Despite this, only four studies reported analgesic use among included patients.

\section{Study variability and recommendations for future research}

Perhaps the most striking finding from this synthesis was the wide variability of results, which was likely due to many factors. Although all studies were prospective cohort studies, study designs differed greatly. There was high heterogeneity in terms of injury types, measures used, and severity of pain, which all may have an impact on the presence of persistent pain and pain intensity. An example of the impact that this variation causes on study results is with respect to the investigation of injury types on the development of persistent pain. Studies that investigated injuries with more general descriptions (eg, upper versus lower extremity injuries or isolated versus multiple injuries) $)^{34,42}$ found significant relationships between injury and the development of persistent pain as compared to those studies that investigated the injuries with a more detailed description (eg, pelvic fracture versus tibial fracture $)^{39}$ as predictive of persistent pain. It appears, therefore, that with a lack of a unified approach in describing the problem of persistent pain in terms of injury types as well as follow-up times, the use of validated pain measures, and the reporting of statistical outputs, it is difficult to investigate 
the aggregated results of the studies included in this review. This phenomenon precluded meta-analysis.

Overall, the results from this systematic review lead to the recommendation that future research studies in the field of traumatic injury use a common and systematic approach in order to better identify the scope and magnitude of those at high-risk of developing persistent pain (Table 5). This can be accomplished by utilizing study designs that explore the development of persistent pain over time (ie, prospective, longitudinal), with an emphasis on obtaining initial assessments as close to the time of the traumatic injury as possible to ensure that the results are able to consider patient presence of pain prior to the injury. At the initial assessment, it is important to use comprehensive and validated measures for pain, following Initiative on Methods, Measurement, and Pain Assessment in Clinical Trials (IMMPACT) guidelines, ${ }^{45}$ and measuring the type and frequency of pain interventions (eg, analgesic consumption, physical therapy, cognitive behavioral therapy). It is also important to follow patients for at least 2 months to determine the incidence of persistent pain. ${ }^{13}$ Due to the variation in methodology between studies, the current review was unable to conduct subanalysis. Therefore, future studies should use unified methodology and validated measures throughout the duration of a study
(Table 5), as it will be easier for researchers to elucidate directionality of pain development following traumatic injury, as is proposed in Figure 1, in order to determine appropriate and timely interventions for this population without overburdening patients and impeding recovery. Only in understanding the presentation of pain amongst patients recovering from musculoskeletal trauma can appropriate interventions be developed. Many of the studies did not report pain intensity; therefore it is difficult to understand the magnitude of the problem at present and therefore difficult to recommend effective pain interventions. However, it is recommended that researchers consider the World Health Organization three-step ladder for pain assessment and management, which describes suitable provision of pharmacological pain interventions according to pain intensity (mild, moderate, and severe), along with psychological and physical interventions. ${ }^{46}$

Another important issue for future research to examine is the extent to which the risk and protective factors involved in the transition to chronicity following traumatic injury differ from those involved in the maintenance of already established chronic pain (eg, see Katz for a similar point with respect to postsurgical pain transition). ${ }^{47}$ This approach highlights the importance of assessing outcomes at multiple time points

Table 5 Road map for future studies assessing the development of persistent pain following traumatic musculoskeletal injury

Study design

- Prospective, longitudinal.

- Initial assessment of all variables should be as close to time of injury as possible.

- Multiple assessment time points for examining change in pain.

- Assessments should correspond to medical and psychological diagnoses, eg, orthopedic healing (3 months), persistent pain ( 2 months), and posttraumatic stress disorder (I month), following date of injury.

Sample

- Participant samples should be clearly described in terms of

$\circ$ Age (mean, range, standard deviation).

- Mechanism of injury (eg, motor vehicle accident, fall).

- Injury type (eg, upper or lower extremity injury, single or multiple injury).

- Sample size should be adequate to have enough power to include all variables being studied in, for example, a logistic regression or hierarchical regression analysis.

- Attrition rates and missing data at each assessment interval.

Pain assessment

- Follow Initiative on Methods, Measurement, and Pain Assessment in Clinical Trials (IMMPACT) guidelines for comprehensive measures of pain. ${ }^{44}$

- Measure the type, amount, and frequency of pain interventions at every pain assessment interval. These may include, but are not limited to, pharmacological interventions (eg, opioid use, nonsteroidal antiinflammatory medications, acetaminophen), psychological (eg, cognitive behavioral therapy, acceptance and commitment therapy), and physical (eg, physiotherapy, ice/heat, massage).

- Pain disability or pain interference must be measured using a reliable, validated measure.

Reported statistics

- Means, standard deviations, and confidence intervals for all variables, where possible.

- Odds ratios (relative risk) and confidence intervals for all models.

Other assessment tools

- All other assessment tools should be well validated and appropriate for assessment among participants who have experienced a traumatic musculoskeletal injury.

- Assessments should be conducted at the time of the initial assessment and at more than one follow-up time point. 
after traumatic injury and implies that the transition to chronic posttraumatic pain and related psychosocial dysfunction is a dynamic process that evolves over time. ${ }^{48}$ Assessing outcomes at a single follow-up point after injury or trauma will not permit an examination of whether the factors involved in the transition to chronicity differ from those involved in the maintenance of already established chronic pain.

\section{Implications of findings for clinical practice}

The current review aimed to synthesize knowledge on the incidence and duration of persistent pain, the relationship between pain intensity and injury severity and type, and the predictors of persistent pain; however, because the results demonstrate that the scope of this knowledge is limited, very few implications for clinical practice can be stated. General trends were able to be observed: a large proportion (28\%-93\%) of patients experiencing TMsI will develop persistent pain for a period of up to 84 months according to some studies, the duration of pain generally decreases over time, and pain intensity may be associated with injury severity and type, where more severe, lower extremity injuries may cause more intense pain than less severe, upper extremity injuries.

Furthermore, as only five studies assessed any psychological outcomes associated with persistent pain, it can only be concluded that anxiety and depression play a role in the onset of poor outcomes as well as the presence of anxiety and depression following traumatic injury.

Despite these facts, it is important to emphasize that a large number of patients experience persistent pain following TMsI. Thus it is essential to (1) provide patients leaving hospital or rehabilitation with guidelines on how to manage any pain they are experiencing, and to (2) follow-up with patients at least 3 months following their injury to provide appropriate interventions (eg, pharmacotherapy, psychotherapy, physiotherapy) while patients are healing from their injuries as earlier interventions may prevent the development of persistent pain.

\section{Conclusion}

The evidence from the eleven studies included in this review indicates that persistent pain is prevalent up to 84 months following traumatic injury. Further research is needed to better evaluate persistent pain and other long-term posttraumatic outcomes. Currently, patients need to be provided with pain management strategies before leaving hospital and informed that they can follow-up with their primary care physician to manage persistent pain, if present.

\section{Disclosure}

The pilot review abstract was previously published in Rosenbloom BN, Khan S, Katz J, et al. Systematic review of persistent pain and psychological outcomes following traumatic musculoskeletal injury. Pain Res Manag. 2012;17(3):222. The results from this search have since been updated and written up in the current manuscript. Joel Katz is supported by a Canadian Research Chair in Health Psychology at York University. Other authors report no conflict of interest in this work.

\section{References}

1. Mock C, Cherian MN. The global burden of musculoskeletal injuries: challenges and solutions. Clin Orthop Relat Res. 2008;466(10): 2306-2316.

2. Cause-specific mortality: regional estimates for 2008: WHO regions [webpage on the Internet]. Geneva: World Health Organization; 2011. Available from: http://www.who.int/healthinfo/global_burden disease/estimates_regional/en/index.html. Accessed November 30, 2012.

3. Krug EG, Sharma GK, Lozano R. The global burden of injuries. Am J Public Health. 2000;90(4):523-526.

4. Canadian Institute for Health Information. National Trauma Registry 2003 Provincial Report, Ontario: Hospital Injury Admissions. Ottawa: Canadian Institute for Health Information; 2003. Available from: https://secure.cihi.ca/free_products/NTRHospInjAdmOntario2003_e. pdf. Accessed November 30, 2012.

5. Bouillon B, Kreder HJ, Eypasch E, et al. Quality of life in patients with multiple injuries - basic issues, assessment, and recommendations. Restor Neurol Neurosci. 2002;20(3-4):125-134.

6. Rivara FP, Mackenzie EJ, Jurkovich GJ, Nathens AB, Wang J, Scharfstein DO. Prevalence of pain in patients 1 year after major trauma. Arch Surg. 2008;143(3):282-287.

7. Haslam L, Sawyer J, Tien H, Restrepo C. The experience of pain after a traumatic injury. Paper presented at: Combined Australasian Trauma Society and Trauma Association of Canada Annual Scientific Meeting; Auckland, New Zealand; March 5-7, 2009.

8. Mkandawire NC, Boot DA, Braithwaite IJ, Patterson M. Musculoskeletal recovery 5 years after severe injury: long term problems are common. Injury. 2002;33(2):111-115.

9. Crombie IK, Davies HT, Macrae WA. Cut and thrust: antecedent surgery and trauma among patients attending a chronic pain clinic. Pain. 1998;76(1-2):167-171.

10. Curran N, Brandner B. Chronic pain following trauma. Trauma. 2005; $7(3): 123-131$

11. Novak CB, Anastakis DJ, Beaton DE, Mackinnon SE, Katz J. Relationships among pain disability, pain intensity, illness intrusiveness, and upper extremity disability in patients with traumatic peripheral nerve injury. J Hand Surg Am. 2010;35(10):1633-1639.

12. Katz J, Page MG. Identification of risk and protective factors in the transition from acute to chronic post surgical pain. In: Lynch ME, Craig D, Peng PWH, editors. Clinical Pain Management: A Practical Guide. Boston, MA: Blackwell Publishing; 2010:32-41.

13. Macrae WA, Davies HTO. Chronic post-surgical pain. In: Crombie IK, Linton S, Croft P, Von Korff M, LeResche L, editors. Epidemiology of Pain. Seattle, WA: IASP Press; 1999:125-142.

14. Ponsford J, Hill B, Karamitsios M, Bahar-Fuchs A. Factors influencing outcome after orthopedic trauma. J Trauma. 2008;64(4): 1001-1009

15. van der Sluis CK, Eisma WH, Groothoff JW, ten Duis HJ. Long-term physical, psychological and social consequences of severe injuries. Injury. 1998;29(4):281-285. 
16. Joy D, Probert R, Bisson JI, Shepherd JP. Posttraumatic stress reactions after injury. J Trauma. 2000;48(3):490-494.

17. Zatzick D, Rivara F, Jurkovich G, et al. Enhancing the population impact of collaborative care interventions: mixed method development and implementation of stepped care targeting posttraumatic stress disorder and related comorbidities after acute trauma. Gen Hosp Psychiatry. 2011;33(2):123-134.

18. Turk DC. A diathesis-stress model of chronic pain and disability following traumatic injury. Pain Res Manag. 2002;7(1):9-19.

19. Martin AL, Halket E, Asmundson GJ, Flora DB, Katz J. Posttraumatic stress symptoms and the diathesis-stress model of chronic pain and disability in patients undergoing major surgery. Clin J Pain. 2010;26(6): 518-527.

20. Sharp TJ, Harvey AG. Chronic pain and posttraumatic stress disorder: mutual maintenance? Clin Psychol Rev. 2001;21(6):857-877.

21. Kleiman V, Clarke H, Katz J. Sensitivity to pain traumatization: a higher-order factor underlying pain-related anxiety, pain catastrophizing and anxiety sensitivity among patients scheduled for major surgery. Pain Res Manag. 2011;16(3):169-177.

22. Bryant RA. Acute stress reactions: can biological responses predict posttraumatic stress disorder? CNS Spectr. 2003;8(9):668-674.

23. Davies M, Brophy S, Williams R, Taylor A. The prevalence, severity, and impact of painful diabetic peripheral neuropathy in type 2 diabetes. Diabetes Care. 2006;29(7):1518-1522.

24. Vlaeyen JW, Linton SJ. Fear-avoidance and its consequences in chronic musculoskeletal pain: a state of the art. Pain. 2000;85(3):317-332.

25. Clay FJ, Watson WL, Newstead SV, McClure RJ. A systematic review of early prognostic factors for persisting pain following acute orthopedic trauma. Pain Res Manag. 2012;17(1):35-44.

26. Nampiaparampil DE. Prevalence of chronic pain after traumatic brain injury: a systematic review. JAMA. 2008;300(6):711-719.

27. Walton DM, Pretty J, MacDermid JC, Teasell RW. Risk factors for persistent problems following whiplash injury: results of a systematic review and meta-analysis. J Orthop Sports Phys Ther. 2009;39(5): 334-350.

28. Henry DE, Chiodo AE, Yang W. Central nervous system reorganization in a variety of chronic pain states: a review. $P M$ R. 2011;3(12): $1116-1125$.

29. Dauber A, Osgood PF, Breslau AJ, Vernon HL, Carr DB. Chronic persistent pain after severe burns: a survey of 358 burn survivors. Pain Med. 2002;3(1):6-17.

30. Moher D, Liberati A, Tetzlaff J, Altman DG; PRISMA Group. Preferred reporting items for systematic reviews and meta-analyses: the PRISMA statement. BMJ. 2009;339:b2535.

31. Downs SH, Black N. The feasibility of creating a checklist for the assessment of the methodological quality both of randomised and nonrandomised studies of health care interventions. J Epidemiol Community Health. 1998;52(6):377-384.

32. Wong EM, Chan SW, Chair SY. Effectiveness of an educational intervention on levels of pain, anxiety and self-efficacy for patients with musculoskeletal trauma. JAdv Nurs. 2010;66(5):1120-1131.

Journal of Pain Research

\section{Publish your work in this journal}

The Journal of Pain Research is an international, peer-reviewed, open access, online journal that welcomes laboratory and clinical findings in the fields of pain research and the prevention and management of pain. Original research, reviews, symposium reports, hypothesis formation and commentaries are all considered for publication.

Submit your manuscript here: http://www.dovepress.com/journal-of-pain-research-journa|
33. Jenewein J, Moergeli H, Wittmann L, Buchi S, Kraemer B, Schnyder U. Development of chronic pain following severe accidental injury. Results of a 3-year follow-up study. J Psychosom Res. 2009;66(2):119-126.

34. Aitken LM, Chaboyer W, Kendall E, Burmeister E. Health status after traumatic injury. J Trauma Acute Care Surg. 2012;72(6):1702-1708.

35. Mayou R, Bryant B. Outcome 3 years after a road traffic accident. Psychol Med. 2002;32(4):671-675.

36. Mayou R, Bryant B. Outcome in consecutive emergency department attenders following a road traffic accident. Br J Psychiatry. 2001;179: $528-534$.

37. Holmes A, Williamson O, Hogg M, et al. Predictors of pain severity 3 months after serious injury. Pain Med. 2010;11(7):990-1000.

38. Norman SB, Stein MB, Dimsdale JE, Hoyt DB. Pain in the aftermath of trauma is a risk factor for post-traumatic stress disorder. Psychol Med. 2008;38(4):533-542.

39. Castillo RC, MacKenzie EJ, Wegener ST, Bosse MJ; Leap Study Group. Prevalence of chronic pain seven years following limb threatening lower extremity trauma. Pain. 2006;124(3):321-329.

40. Sanders DW, MacLeod M, Charyk-Stewart T, Lydestad J, Domonkos A, Tieszer C. Functional outcome and persistent disability after isolated fracture of the femur. Can J Surg. 2008;51(5):366-370.

41. Clay FJ, Newstead SV, Watson WL, Ozanne-Smith J, Guy J, McClure RJ. Bio-psychosocial determinants of persistent pain 6 months after non-life-threatening acute orthopaedic trauma. J Pain. 2010;11(5): $420-430$.

42. Michaels AJ, Madey SM, Krieg JC, Long WB. Traditional injury scoring underestimates the relative consequences of orthopedic injury. J Trauma. 2001;50(3):389-395.

43. Williamson OD, Epi GD, Gabbe BJ, et al. Predictors of moderate or severe pain 6 months after orthopaedic injury: a prospective cohort study. J Orthop Trauma. 2009;23(2):139-144.

44. Dobscha SK, Clark ME, Morasco BJ, Freeman M, Campbell R, Helfand M. Systematic review of the literature on pain in patients with polytrauma including traumatic brain injury. Pain Med. 2009;10(7):1200-1217.

45. Turk DC, Dworkin RH, Allen RR, et al. Core outcome domains for chronic pain clinical trials: IMMPACT recommendations. Pain. 2003;106(3):337-345.

46. The British Pain Society. Opioids for Persistent Pain: Good Practice. London: The British Pain Society; 2010. Available from: http://www. britishpainsociety.org/book_opioid_main.pdf. Accessed November 30, 2011.

47. Katz J. One man's risk factor is another man's outcome: difference in risk factor profiles for chronic postsurgical pain maintenance vs transition. Pain. 2012;153(3):505-506.

48. Katz J, Seltzer Z. Transition from acute to chronic postsurgical pain: risk factors and protective factors. Expert Rev Neurother. 2009;9(5): 723-744.

The manuscript management system is completely online and includes a very quick and fair peer-review system, which is all easy to use. Visit http://www.dovepress.com/testimonials.php to read real quotes from published authors.

\section{Dovepress}

